\title{
Acute complications and mortality in hospitalized patients with coronavirus disease 2019: a systematic review and meta-analysis
}

Nicola Potere ${ }^{1 \dagger}$, Emanuele Valeriani ${ }^{i^{* \dagger}}$ (D) Matteo Candeloro ${ }^{2}$, Marco Tana ${ }^{1}$, Ettore Porreca ${ }^{1}$, Antonio Abbate ${ }^{3}$, Silvia Spoto ${ }^{4}$, Anne W. S. Rutjes ${ }^{5}$ and Marcello Di Nisio ${ }^{2,6}$

\begin{abstract}
Background: The incidence of acute complications and mortality associated with COVID-19 remains poorly characterized. The aims of this systematic review and meta-analysis were to summarize the evidence on clinically relevant outcomes in hospitalized patients with COVID-19.
\end{abstract}

Methods: MEDLINE, EMBASE, PubMed, and medRxiv were searched up to April 20, 2020, for studies including hospitalized symptomatic adult patients with laboratory-confirmed COVID-19. The primary outcomes were all-cause mortality and acute respiratory distress syndrome (ARDS). The secondary outcomes included acute cardiac or kidney injury, shock, coagulopathy, and venous thromboembolism. The main analysis was based on data from peer-reviewed studies. Summary estimates and the corresponding 95\% prediction intervals (PIs) were obtained through meta-analyses.

Results: A total of 44 peer-reviewed studies with 14,866 COVID-19 patients were included. In general, risk of bias was high. All-cause mortality was 10\% overall (95\% Pl, 2 to 39\%; 1687/14203 patients; 43 studies), 34\% in patients admitted to intensive care units (95\% Pl, 8 to 76\%; 659/2368 patients; 10 studies), $83 \%$ in patients requiring invasive ventilation (95\% PI, 1 to 100\%; 180/220 patients; 6 studies), and 75\% in patients who developed ARDS (95\% PI, 35 to 94\%; 339/455 patients; 11 studies). On average, ARDS occurred in 14\% of patients (95\% PI, 2 to 59\%; 999/6322 patients; 23 studies), acute cardiac injury in 15\% (95\% PI, 5 to 38\%; 452/2389 patients; 10 studies), venous thromboembolism in 15\% (95\% Pl, 0 to 100\%; patients; 3 studies), acute kidney injury in 6\% (95\% PI, 1 to 41\%; 318/4682 patients; 15 studies), coagulopathy in 6\% (95\% $\mathrm{Pl}, 1$ to 39\%; 223/3370 patients; 9 studies), and shock in 3\% (95\% Pl, 0 to 61\%; 203/4309 patients; 13 studies).

Conclusions: Mortality was very high in critically ill patients based on very low-quality evidence due to striking heterogeneity and risk of bias. The incidence of clinically relevant outcomes was substantial, although reported by only one third of the studies suggesting considerable underreporting.

Trial registration: PROSPERO registration ID for this study is CRD42020177243 (https:/www.crd.york.ac.uk/prospero/ display_record.php?RecordID=177243).

Keywords: Adult respiratory distress syndrome, Coronavirus, COVID-19, Oxygen inhalation therapy, SARS virus

\footnotetext{
* Correspondence: emanuele.valeriani@outlook.com

${ }^{\dagger}$ Nicola Potere and Emanuele Valeriani shared first co-authorship

'Department of Medical, Oral and Biotechnological Sciences, "G. D'Annunzio"

University, Via Dei Vestini 31, 66100 Chieti, Italy

Full list of author information is available at the end of the article
}

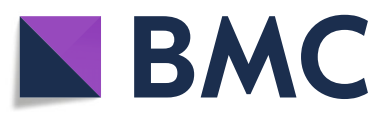

(c) The Author(s). 2020 Open Access This article is licensed under a Creative Commons Attribution 4.0 International License, which permits use, sharing, adaptation, distribution and reproduction in any medium or format, as long as you give appropriate credit to the original author(s) and the source, provide a link to the Creative Commons licence, and indicate if changes were made. The images or other third party material in this article are included in the article's Creative Commons licence, unless indicated otherwise in a credit line to the material. If material is not included in the article's Creative Commons licence and your intended use is not permitted by statutory regulation or exceeds the permitted use, you will need to obtain permission directly from the copyright holder. To view a copy of this licence, visit http://creativecommons.org/licenses/by/4.0/ The Creative Commons Public Domain Dedication waiver (http://creativecommons.org/publicdomain/zero/1.0/) applies to the data made available in this article, unless otherwise stated in a credit line to the data. 


\section{Background}

Clinical manifestations of Coronavirus disease 2019 (COVID-19) range from mild cases to severe pneumonia, which may be complicated by an exaggerated systemic inflammatory response leading to acute respiratory distress syndrome (ARDS), multiple organ failure, and death [1-3]. The largest report on COVID-19 from the Chinese Center for Disease Control and Prevention showed that among 44, 672 confirmed cases, $80.9 \%$ were mild, $13.9 \%$ severe, and $4.7 \%$ critical. The overall case-fatality rate was $2.3 \%$ with values as high as $49 \%$ in critical patients with respiratory failure, septic shock, or multiple organ failure [4].

Since the start of the outbreak, observational studies have extensively described the most prevalent clinical, laboratory, and radiological presentations of COVID-19. However, the clinical course of patients with COVID-19 remains poorly characterized, with heterogeneous and discordant incidence of in-hospital complications and mortality [5-7].

The aims of this systematic review and meta-analysis were to evaluate current evidence on clinically relevant outcomes in hospitalized symptomatic adult patients with COVID-19 and identify factors which may predict worse prognosis.

\section{Methods}

This study-level systematic review and meta-analysis was performed following the Preferred Reporting Items for Systematic reviews and Meta-analysis (PRISMA) guidelines [8].

The PROSPERO registration ID is CRD42020177243.

\section{Databases search and study selection}

MEDLINE, EMBASE (Ovid-SP), and PubMed were searched from inception up to April 20, 2020, for observational studies and randomized controlled trials (RCTs) in English language which included symptomatic adult patients with COVID-19. This search was complemented with the screening of medRxiv, a free online archive for complete but unpublished manuscripts (preprints) in the health sciences (https://www.medrxiv.org/content/ about-medrxiv), until April 20, 2020. The preprints available in medRxiv represent preliminary reports of studies that have not been peer-reviewed yet; thus, they may help to provide a comprehensive picture of the evidence that may be published in future, but they should not be relied on to guide clinical practice. The complete search strategy is given in Additional file 1: Tables S1 and S2.

Two authors independently reviewed titles and abstracts identified from the search to select studies which met the following inclusion criteria: (i) observational study or RCT enrolling $\geq 50$ symptomatic outpatients or hospitalized patients, (ii) laboratory-confirmed COVID-19 defined by a positive result on a reverse-transcriptase-polymerasechain-reaction assay of a nasopharyngeal and oropharyngeal swabs or a sputum specimen, and (iii) at least one of the primary outcomes reported by the study. Case reports and case series with less than 50 patients were excluded as they may observe no events due to the small size. Full-text screening was done independently by the same authors, and any disagreement was resolved through discussion or involving a third review author.

\section{Data extraction and quality assessment}

Two review authors independently extracted data from the included studies. Any disagreement was resolved by consensus between the two review authors or by involving a third review author. The following data were extracted: study characteristics (e.g., study design, health-care setting), patients' characteristics (e.g., age, sex), presence of comorbidities (e.g., respiratory system disease, chronic kidney disease, cardiovascular disease, diabetes, hypertension, malignancy), severity of COVID-19 disease at study entry, treatment (e.g., antivirals, antibiotic therapy, invasive ventilation and non-invasive oxygen support), and clinical outcomes. We extracted the number of patients with severe COVID-19 at study entry and recorded for each study whether internationally accepted criteria or authors' own definitions were used [9-11].

The methodological quality was evaluated using the methodological index for non-randomized studies (MINORS) tool for observational studies and the Cochrane tool for RCTs [12, 13]. The MINORS tool evaluates eight study quality items and classifies them as adequate, inadequate, or unclear [12]. The MINORS' item on blinded evaluation was deemed adequate for ARDS if an external independent adjudication committee was involved. The item related to the endpoint definition was considered adequate if unambiguous criteria were used to define the review outcomes. Follow-up duration was considered adequate if all included patients were followed up until hospital discharge or death.

\section{Study outcomes}

The primary outcomes were all-cause mortality and ARDS. The secondary outcomes included shock, acute kidney injury, acute cardiac injury, coagulopathy, venous thromboembolism, and major bleeding events.

It was anticipated that outcome definitions varied across included studies. This aspect was considered in the evaluation of the study quality item regarding the appropriateness of the criteria used to define the primary outcomes. Standard criteria to diagnose the outcomes of interest included the following: ARDS diagnosed according to the Berlin definition [14]; shock defined as persisting hypotension despite volume resuscitation, requiring vasopressors to maintain mean arterial pressure $\geq 65$ 
$\mathrm{mmHg}$ and serum lactate level $>2 \mathrm{mmol} / \mathrm{L}$ [15]; acute kidney injury diagnosed as an increase in serum creatinine by $\geq 0.3 \mathrm{mg} / \mathrm{dl}$ within $48 \mathrm{~h}, \geq 1.5$ times from baseline within 7 days, or urine volume $<0.5 \mathrm{ml} / \mathrm{kg} / \mathrm{h}$ for $6 \mathrm{~h}$ [16]; acute myocardial injury diagnosed when there was a rise and/or fall of cardiac troponin values with at least one value above the 99th percentile of the upper reference limit [17]; coagulopathy including the development of disseminated intravascular coagulopathy defined according to the International Society of Thrombosis and Hemostasis [18], or abnormal values of specific coagulation markers [19]; venous thromboembolism including fatal or non-fatal pulmonary embolism and deep vein thrombosis; and major bleeding defined according to the criteria of the International Society of Thrombosis and Hemostasis [20].

\section{Statistical analysis}

The main analysis was based on data extracted from peer-reviewed studies that were retrieved from MEDLINE, EMBASE, and PubMed databases. The analyses performed on not peer-reviewed studies retrieved from medRxiv were considered exploratory.

For descriptive purposes, we used the mean and standard deviation for continuous variables or the median and range, where appropriate. Categorical variables were described as counts and percentages. Summary estimates and the corresponding 95\% prediction intervals (PIs) and 95\% confidence intervals (CIs) were obtained through meta-analyses. PIs show the extent of betweenstudy variation and predict the possible effect in a future study that is comparable to those included in the metaanalysis. Single proportions were logit transformed to maintain symmetry in the random effects meta-analysis. Confidence intervals for individual studies were estimated with the Wilson score. Heterogeneity across the included studies was evaluated by visual inspection of forest plots, as estimates of $I$-squared are uninformative in meta-analyses of single proportions. Stratified random-effects meta-analyses were planned to evaluate the impact on mortality of COVID-19 severity at study entry (i.e., severe vs non-severe), older age ( $<60$ vs $\geq 60$ years), presence of comorbidities, concomitant arterial hypertension, admission to intensive care unit (ICU), and requirement for invasive ventilation, if at least 10 studies contributed to the analyses. Stratified analyses were planned only for peer-reviewed studies. The incidence of all-cause mortality in patients developing ARDS was also evaluated in stratified analysis. Severe cases of COVID-19 develop complications like ARDS, shock, acute kidney injury, or cardiac injury more often during the first 2 weeks of hospitalization [9]. Thus, an additional stratified analysis was planned to explore the effects of follow-up duration on the primary outcomes comparing adequate follow-up duration versus inadequate follow-up duration [21].

Statistical analyses were performed using $\mathrm{R}$ studio version 1.2.5001, "meta" and "forestplot" packages [22].

\section{Results}

A total of 4540 records were identified from the search of MEDLINE, EMBASE, and PubMed databases, and 1559 additional records were found in the medRxiv archive (Additional file 1: Fig. S1). After removing 1642 duplicates, 4354 records were excluded based on title and abstract screening. Of the remaining 103 records, 24 were excluded by full-text evaluation. Finally, a total of 44 peerreviewed studies (one RCT and 43 observational studies) including 14,866 patients with laboratory-confirmed COVID-19 were considered in the primary analysis [1, 23-65], and 35 not peer-reviewed studies (one RCT and 34 observational studies) including 11,283 patients were evaluated in the secondary analysis (Additional file 1). The inter-reviewer agreement was excellent with a kappa statistic of 0.92 .

\section{Characteristics of included studies}

The main characteristics of peer-reviewed studies are reported in Additional file 1: Table S3. Forty-one studies were conducted in China or other Asian countries, 2 in Western Europe, and 1 involved centers from the USA, Canada, Europe, and Japan. Twenty-eight studies (63.6\%) were single centre and $16(36.4 \%)$ multicentre. The size of the study population ranged from 52 to 1591 patients. Forty-three studies (97.7\%) enrolled only hospitalized patients, while one study considered both outpatients and inpatients. Median hospital stay was 15 days (range 8 to 29; 12 studies). All studies reported at least one of the review primary outcomes, and 15 (34.1\%) provided data on one or more secondary outcomes.

The risk of bias of the peer-reviewed RCT was high for blinding of participants and personnel, unclear for blinding of outcome assessors, and low for all other domains. The methodological quality of the 43 observational studies, one ambispective and 42 retrospective cohorts, is summarized in Additional file 1: Fig. S2 and Table S4. Sixteen studies (37\%) reported consecutive inclusion of patients. Follow-up duration was adequate in seven studies and reported to be at least 2 weeks in thirteen studies. The main characteristics of not peerreviewed studies are shown in Additional file 1: Tables S5 and S6.

\section{Patient characteristics}

The main patient characteristics reported in peerreviewed studies are given in Additional file 1: Table S7. The mean age ranged between 38 and 69 years, and $8370(56.4 \%)$ patients were males. The most common 
symptoms on admission were fever (7853/9822 patients [79.9\%]; 32 studies), cough (5965/9487 patients [62.9\%]; 30 studies), and dyspnea (2067/8810 patients [23.5\%]; 25 studies). The most common comorbidities were hypertension (2409/10310 patients [23.3\%]; 29 studies), diabetes (1116/10435 patients [10.7\%]; 31 studies), cardiovascular disease (1018/10782 patients [9.4\%]; 32 studies), and cancer (397/11019 patients [3.6\%]; 29 studies). Pre-existent respiratory system disease was reported in $2.8 \%$ of patients (312/11033 patients; 30 studies). Coinfection was diagnosed in $14.0 \%$ of patients $(255 / 1815$ patients; 10 studies).

Twenty-nine studies (65.9\%) reported the severity of COVID-19 at study entry according to the criteria of American Thoracic Society (3 studies), the National Health Commission of the People's Republic of China (10 studies), the World Health Organization criteria (9 studies), or other classifications (7 studies). As many as $41.3 \%(5175 / 12530)$ of patients were considered to have severe COVID-19 at study entry.

Most patients were managed in general wards, and $34.6 \%$ (2659/7687; 18 studies) were admitted to ICU. Supplemental oxygen was administered to $36.3 \%$ of patients (1959/5392; 18 studies), non-invasive ventilation to $8.7 \%$ (589/6797; 20 studies), and invasive-mechanical ventilation to $18.5 \%$ (1644/8901; 21 studies; see Additional file 1: Table S8), whereas $0.9 \%$ of the patients required extracorporeal membrane oxygenation (39/4412; 16 studies). Continuous renal replacement therapy was used in $1.9 \%$ of patients $(86 / 4601 ; 14$ studies).

The main characteristics of patients included in not peer-reviewed studies are reported in Additional file 1: Table S9. Twenty-four not peer-reviewed studies (68.6\%) reported the severity of COVID-19 according to the criteria of American Thoracic Society (2 studies), the National Health Commission of the People's Republic of China (4 studies), the World Health Organization criteria (4 studies), or other classifications (14 studies). As many as $31.8 \%(1902 / 5975)$ of patients of not peer-reviewed studies were considered to have severe COVID-19 at study entry. The type of treatment provided in not peerreviewed studies is shown in Additional file 1: Table S10.

\section{Clinical outcomes}

Figure 1 shows all-cause mortality in peer-reviewed studies from Asian and Western countries, sorted by severity of COVID-19 at study entry and the proportion of patients admitted to ICU. The summary estimate for allcause mortality was $10 \%$ with substantial between-study heterogeneity and large 95\% PI (95\% PI, 2 to 39\%; 1687/ 14203 patients; 43 studies) suggesting high uncertainty. All-cause mortality was $34 \%$ in patients admitted to ICU (95\% PI, 8 to $76 \%$; 659/2368 patients; 10 studies), $83 \%$ in patients requiring invasive ventilation (95\% PI, 1 to
$100 \%$; $180 / 220$ patients; 6 studies), and $75 \%$ in patients who developed ARDS (95\% PI, 35 to 94\%; 339/455 patients; 11 studies) with very high between-study heterogeneity (Figure 2). All-cause mortality in patients with advanced age, one or more comorbidities, concomitant arterial hypertension, and severe COVID-19 at study entry and in studies with adequate follow-up is shown in Additional file 1: Fig. S3.

Figure 3 shows ARDS outcome data in peer-reviewed studies from Asian and Western countries sorted for severity of COVID-19 at study entry and the proportion of patients admitted to the ICU. On average, ARDS occurred in $14 \%$ of patients with significant between-study heterogeneity (95\% PI, 2 to 59\%; 999/6322 patients; 23 studies). Studies with follow-up until patient discharge or death reported significantly higher ARDS risks compared to studies with inadequate follow-up duration ( $28 \%$ vs $11 \%$; $p=0.002$; Additional file 1: Fig. S4).

Figures 4 and 5 and Additional file 1: Table S11 show outcome data for the secondary outcomes. In peerreviewed studies, the average summary estimates were $15 \%$ for acute cardiac injury (95\% PI, 5 to $38 \%$; $452 / 2389$ patients; 10 studies), $15 \%$ for venous thromboembolism (95\% PI, 0 to 100\%; patients; 3 studies), $6 \%$ for acute kidney injury (95\% PI, 1 to 41\%; 318/4682 patients; 15 studies), $6 \%$ for coagulopathy (95\% PI, 1 to 39\%; 223/3370 patients; 9 studies), and 3\% for shock (95\% PI, 0 to 61\%; 203/4309 patients; 13 studies). Major bleeding events were reported in one study (2/199 patients; $1.0 \%)$.

The incidence of the primary and secondary outcomes in not peer-reviewed studies was consistent with that of the primary analysis (Additional file 1: Table S12 and Figs. S5 to S10). As observed in peer-reviewed studies, all summary estimates for primary and secondary outcomes presented significant between-study heterogeneity and wide prediction intervals.

\section{Discussion}

In this meta-analysis including 14,866 symptomatic adult patients with COVID-19, all-cause mortality was $10 \%$. The incidence seemed three to eightfold higher in patients admitted to ICU, requiring invasive ventilation, and those who developed ARDS based on very low quality evidence due to heterogeneity and risk of bias.

On average, mortality of COVID-19 patients admitted to ICU was $34 \%$, consistent with the results of a recent large study of ICU patients with infection of the respiratory tract or other sites [66]. In ICU patients as well as in those requiring invasive ventilation or developing ARDS, prediction intervals were wide indicating very low confidence in the summary estimates. Overall, these findings suggest that different case mix with different prognosis were included in the studies. Potential explanation for heterogeneity include differences in age and 


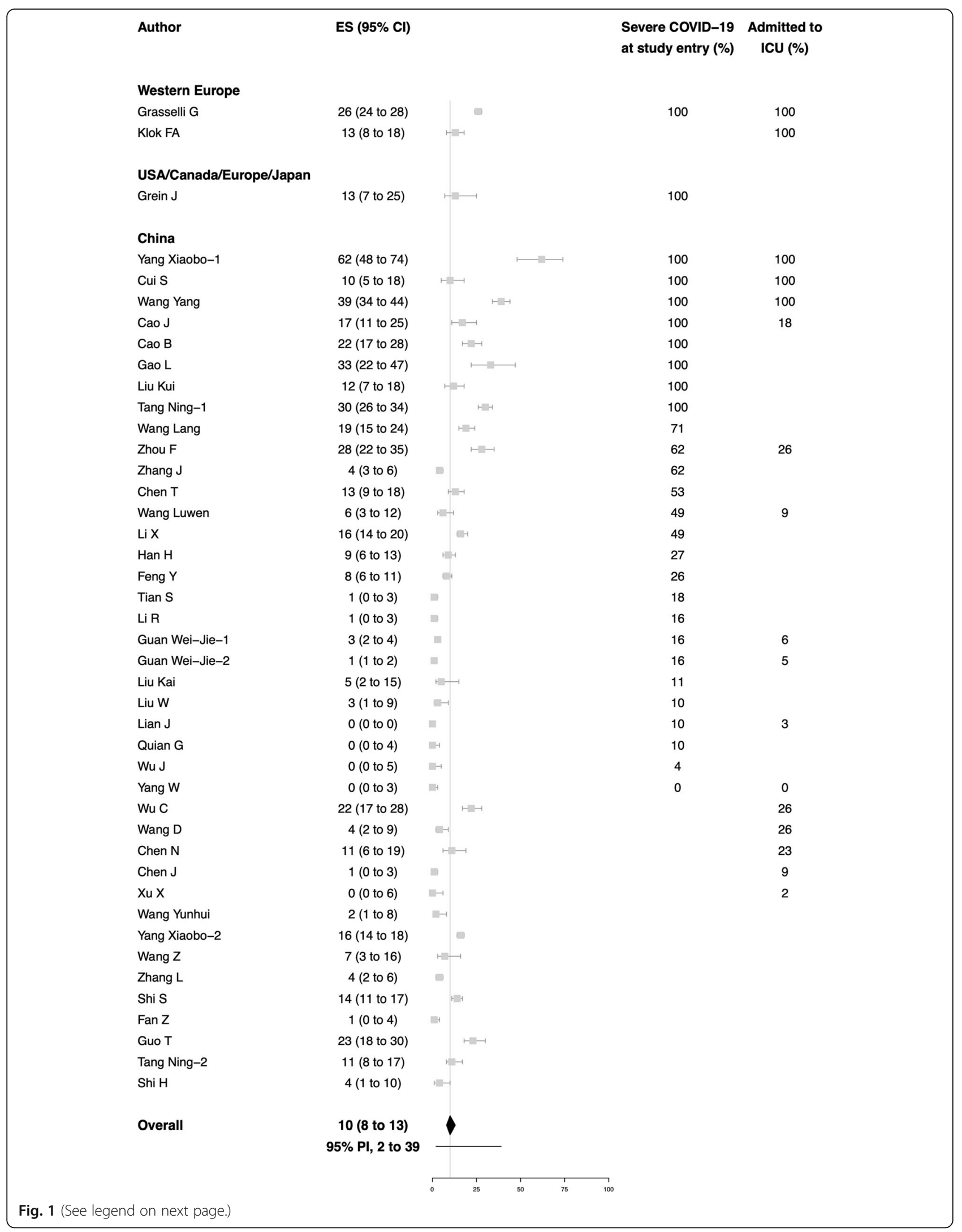


(See figure on previous page.)

Fig. 1 All-cause mortality in patients with COVID-19. All-cause mortality in peer-reviewed studies from Asian and Western countries, sorted by severity of COVID-19 at study entry and the proportion of patients admitted to ICU. The vertical line indicates the summary estimate. Gray squares indicate individual study estimates of the proportion of all-cause mortality, whereas the gray horizontal lines indicate $95 \%$ confidence intervals of the individual studies. The diamond indicates the summary estimate with $95 \%$ confidence intervals. The horizontal black line refers to the prediction intervals which are displayed numerically under the $95 \%$ confidence intervals. Cl, confidence intervals; COVID-19, Coronavirus disease 2019; ES, estimates; ICU, intensive care unit; Pl, prediction intervals; USA, United States of America

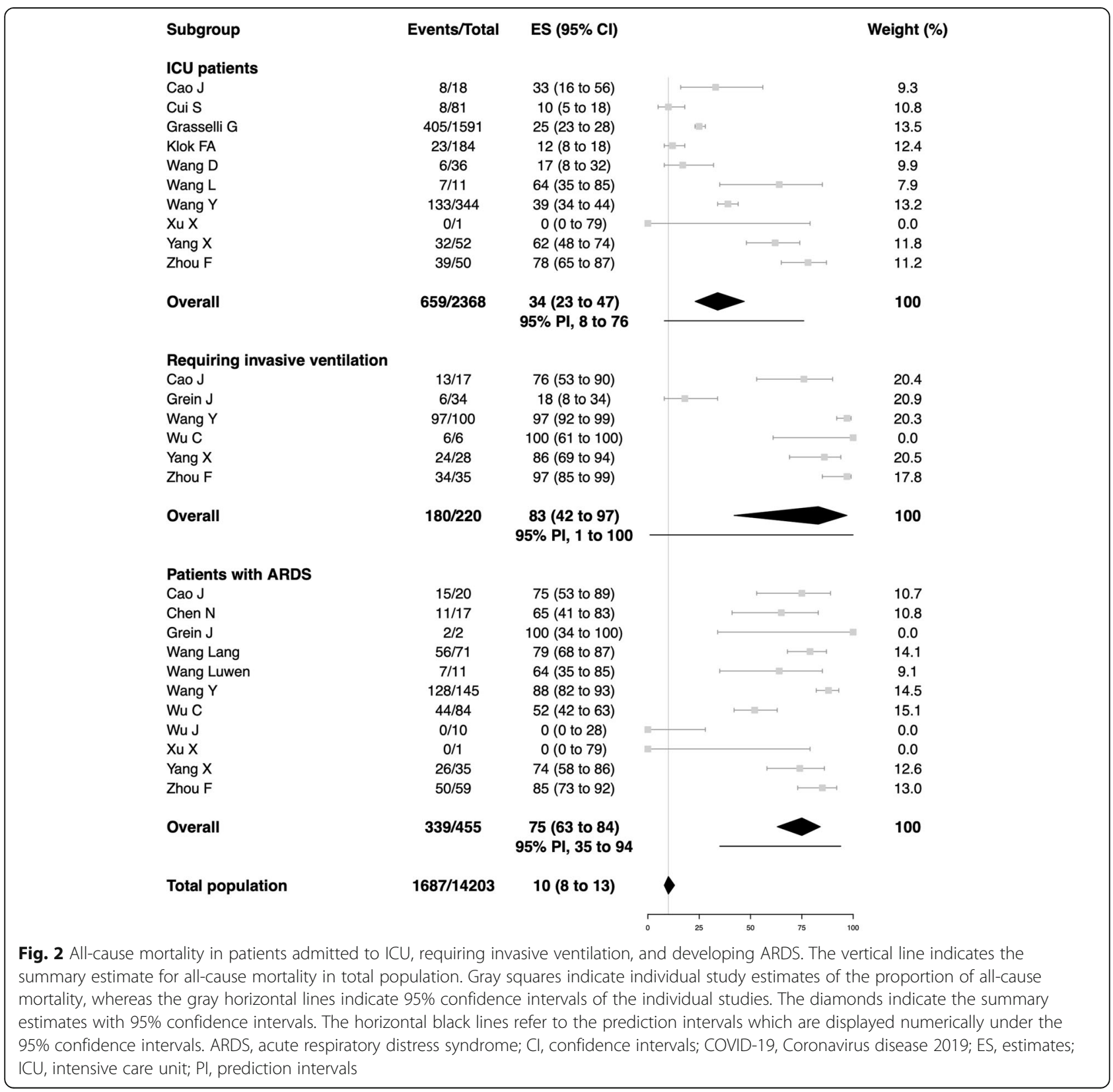




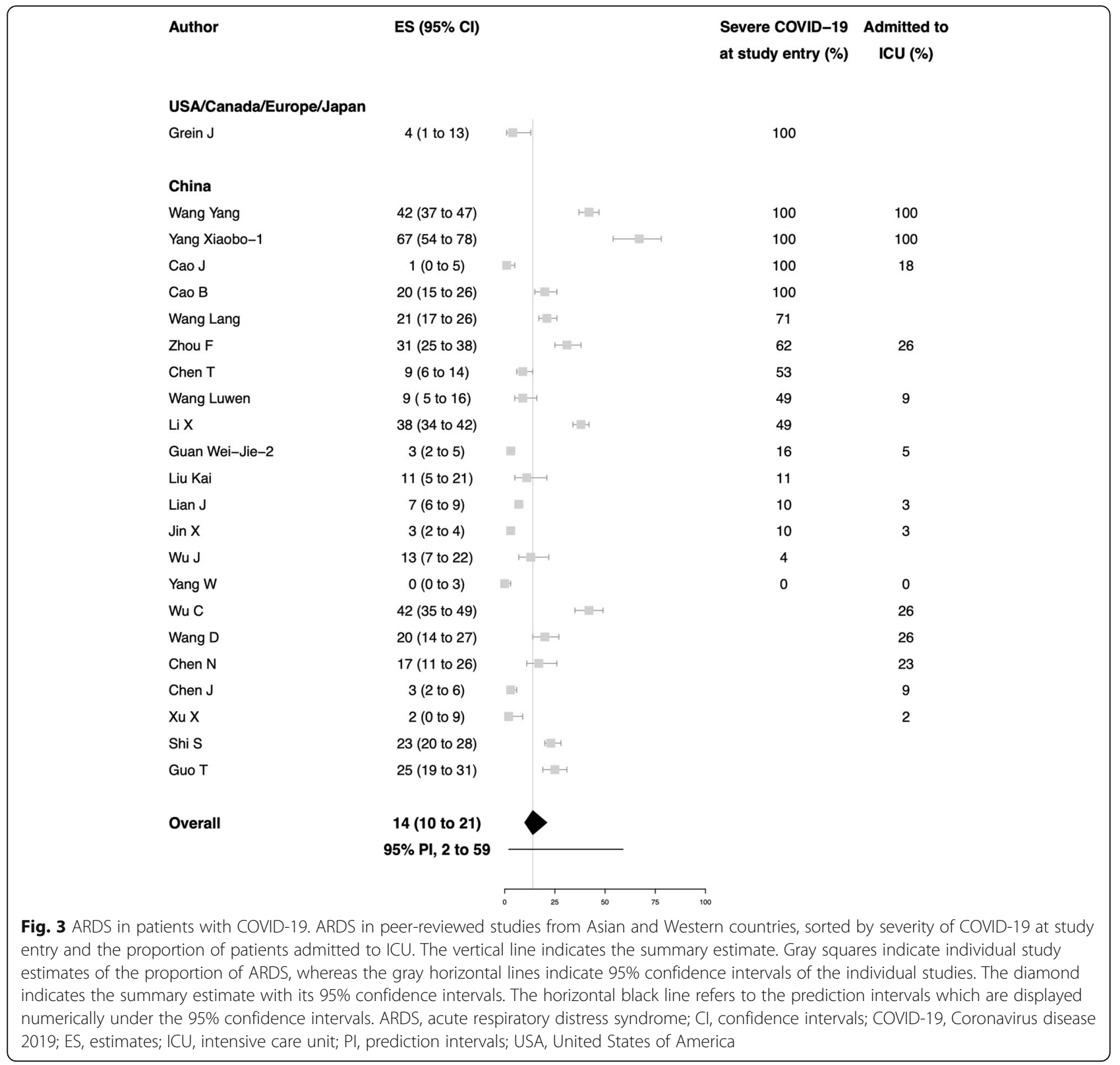

comorbidities between study populations, definition of COVID-19-related deaths, and susceptibility or response to COVID-19 [6, 67, 68]. Another potential explanation for the heterogeneous risks of mortality and ARDS may be related to the insufficient length of follow-up. The proportion of patients who were still hospitalized at the end of the study period was as high as $31.9 \%$ (Additional file 1 : Tables S11). The clinical outcomes of these patients remain unknown, which may have underestimated the actual incidence of complications which typically tend to occur during the late hyperinflammatory phase of the disease. Only 7 studies followed patients until death or discharge, and 13 studies had a follow-up of at least 14 days, which may be regarded as a minimum follow-up duration to observe clinically relevant outcomes [21]. Stratified analysis suggested that mortality and ARDS were significantly higher in studies with adequate (20\% and $28 \%$ ) compared to those with inadequate follow-up duration $(9 \%$ and $11 \%$, respectively).

With regard to the secondary outcomes of this metaanalysis, acute cardiac injury and venous thromboembolism seemed to represent the most frequent complications during hospitalization, followed by acute kidney injury, coagulopathy, and shock. As observed for the primary outcomes, the uncertainty around all these estimates was large. Importantly, information on secondary outcomes was provided by only one third of the studies, suggesting significant underreporting. In addition, it is unclear if 


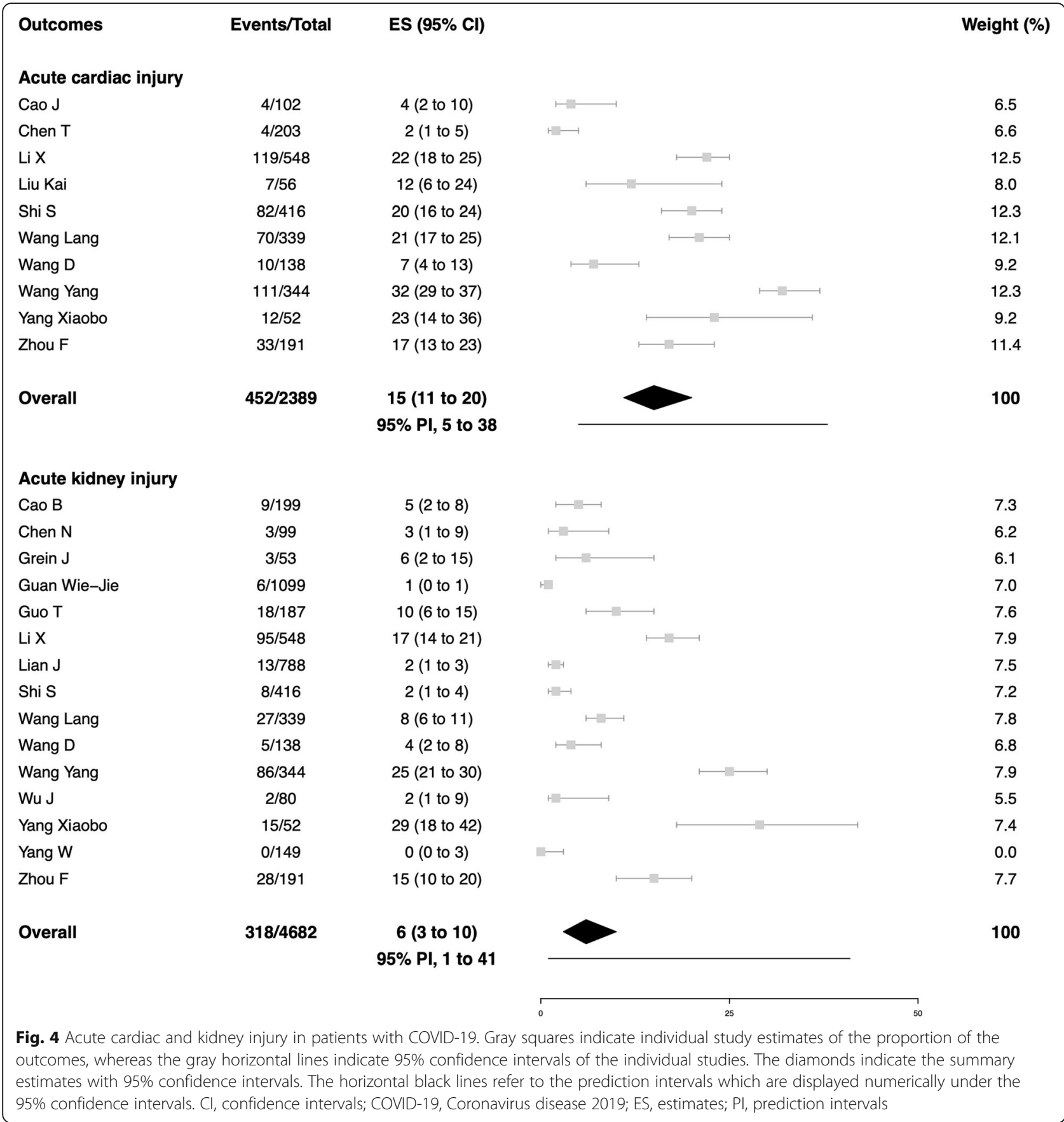

these outcomes were systematically evaluated in all patients, and we cannot exclude that our summary estimates may represent an underestimation of actual incidence. Nonetheless, our findings suggest that these acute complications are not infrequent and may have a relevant impact on patient prognosis and burden for health care systems. A better understanding of the risk and prompt recognition of these complications could help to improve policies for diagnosis and prevention, resource allocation, and help the design of future interventional studies.
The current review has some limitations which need to be discussed. Most studies were conducted in China or other Asian countries which contributed to $88.1 \%$ of all patients. The different accessibility and quality of health care settings and resources within each country and between countries may influence the representation of clinical outcomes and limit interpretation of some of the findings. Most studies were retrospective, and it was often unclear whether patients were enrolled consecutively. The need to provide objective findings 


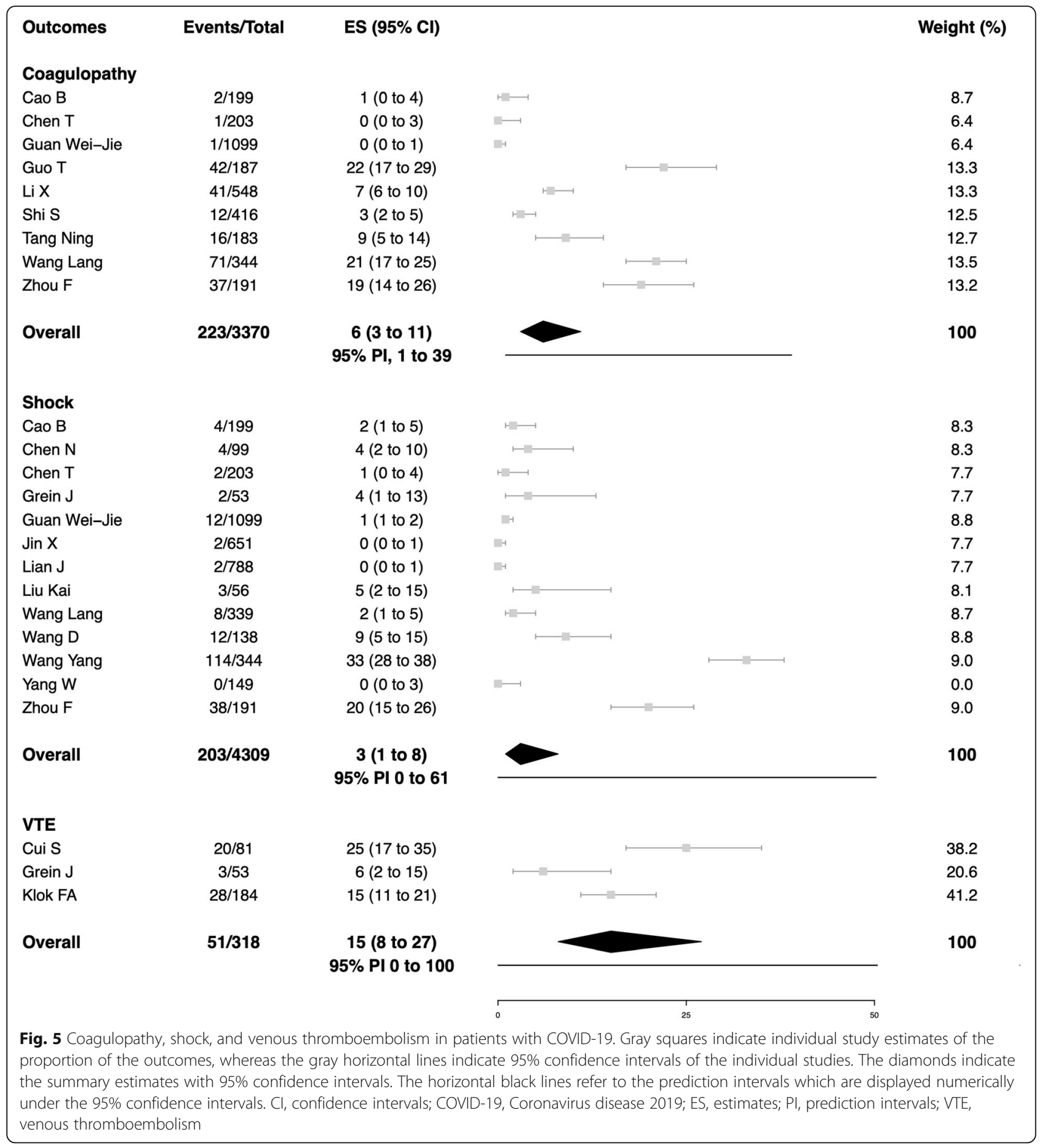

and the urgent timeline of the disease may have affected the quality of data recording and reporting. The study-level analysis and poor reporting limited the possibility to evaluate the effects of specific patient characteristics, type of medical and supportive treatment (e.g., requirement for kidney replacement therapy) on clinical outcomes. All outcomes were provided as crude proportions rather than time-to- event rates (e.g., events per 100 patient days), which incorporate a measure of the at-risk period, thereby giving a more standardized and less biased summary estimate. Finally, in light of the large between-study heterogeneity observed, pooling of the individual study estimates is debatable. For this reason, we focused on the prediction interval rather than the confidence interval when describing results. 


\section{Conclusions}

This systematic review and meta-analysis summarized the current evidence on the incidence of mortality and acute complications in hospitalized patients with COVID-19. Mortality was very high in critically ill patients, based on very low-quality evidence with striking heterogeneity. Health care professionals caring for COVID-19 patients need to be aware of this variability for medical decision making and communication.

\section{Supplementary information}

Supplementary information accompanies this paper at https://doi.org/10. 1186/s13054-020-03022-1.

Additional file 1: Table S1. Search strategy, update in Embase and Medline. Table S2. Search strategy in Pubmed. Table S3. Characteristics of peer-reviewed studies. Table S4. MINORS quality assessment for peerreviewed studies. Table S5. Characteristics of not peer-reviewed studies. Table S6. MINORS quality assessment for not peer-reviewed studies. Table S7. Patient demographics and clinical characteristics at study entry in peer-reviewed studies. Table S8. Treatment provided in peer-reviewed studies. Table S9. Patient demographics and clinical characteristics at study entry in not peer-reviewed studies. Table S10. Treatment provided in not peer-reviewed studies. Table S11. Clinical outcomes of patients in peer-reviewed studies. Table S12. Clinical outcomes of patients in not peer-reviewed studies. Fig. S1. PRISMA flow diagram. Fig. S2. MINORS quality assessment for peer reviewed (panel A) and not peer-reviewed (panel B) studies. Fig. S3. All-cause mortality by subgroup of patients with COVID-19, peer-reviewed studies. Fig. S4. ARDS by follow-up duration, peer-reviewed studies. Fig. S5. All-cause mortality in patients with COVID-19, not peer-reviewed studies. Fig. S6. ARDS in patients with COVID-19, not peer-reviewed studies. Fig. S7. Acute cardiac injury in patients with COVID-19, not peer-reviewed studies. Fig. S8. Acute kidney injury in patients with COVID-19, not peer-reviewed studies. Fig. S9. Coagulopathy in patients with COVID-19, not peer-reviewed studies. Fig. S10. Shock in patients with COVID-19, not peer-reviewed studies.

\section{Abbreviations}

ARDS: Acute respiratory distress syndrome; Cls: Confidence intervals;; COVID19: Coronavirus disease 2019; ICU: Intensive care unit; MINORS: Methodological index for non-randomized studies; Pls: Prediction intervals; PRISMA: Preferred Reporting Items for Systematic reviews and Meta-analysis; RCTs: Randomized controlled trials

\section{Acknowledgements}

Not applicable.

\section{Authors' contributions}

EV have full access to all of the data in the study. All authors of the manuscript are accountable for all aspects of the accuracy and integrity of the manuscript. Study conception and design: EV, MDN, and AR; data acquisition: NP, MC, and MDN; statistical analysis: AR, EV, and MDN; interpretation of the data: all authors; drafting of the manuscript: all authors; critical revision of the manuscript for important intellectual content: all authors; Final approval of the manuscript: all authors.

\section{Funding}

There was no funding source for this study.

\section{Availability of data and materials}

The datasets used and/or analyzed during the current study are available from the corresponding author on reasonable request.

Ethics approval and consent to participate Not applicable.
Consent for publication

Not applicable.

\section{Competing interests}

$N P, E V, M C, M T, E P, A A, S S$, and AR have no competing interests. MDN reports personal fees from Bayer, Daiichi Sankyo, Sanofi, Pfizer, Leo Pharma, and Aspen outside the submitted work.

\section{Author details}

'Department of Medical, Oral and Biotechnological Sciences, "G. D'Annunzio" University, Via Dei Vestini 31, 66100 Chieti, Italy. ${ }^{2}$ Department of Medicine and Ageing Sciences, "G. d'Annunzio" University, Chieti-Pescara, Italy. ${ }^{3}$ VCU Heart Center, Virginia Commonwealth University, Richmond, VA, USA.

${ }^{4}$ Internal Medicine Department, University Hospital Campus Bio-Medico, Rome, Italy. ${ }^{5}$ Institute of Social and Preventive Medicine (ISPM), University of Bern, Bern, Switzerland. ${ }^{6}$ Department of Vascular Medicine, Academic Medical Center, Amsterdam, The Netherlands.

Received: 1 May 2020 Accepted: 25 May 2020

Published online: 02 July 2020

\section{References}

1. Chen N, Zhou M, Dong X, Qu J, Gong F, Han Y, et al. Epidemiological and clinical characteristics of 99 cases of 2019 novel coronavirus pneumonia in Wuhan, China: a descriptive study. Lancet. 2020;395(10223):507-13.

2. Siddiqi HK, Mehra MR. COVID-19 illness in native and immunosuppressed states: a clinical-therapeutic staging proposal. The Journal of Heart and Lung Transplantation. 2020;39(5):405-407.

3. Mehta P, McAuley DF, Brown M, Sanchez E, Tattersall RS, Manson JJ, et al. COVID-19: consider cytokine storm syndromes and immunosuppression. Lancet. 2020;395(10229):1033-4.

4. Wu Z, McGoogan JM. Characteristics of and important lessons from the coronavirus disease 2019 (COVID-19) outbreak in China: summary of a report of 72314 cases from the Chinese Center for Disease Control and Prevention. JAMA. 2020.

5. Rodriguez-Morales AJ, Cardona-Ospina JA, Gutierrez-Ocampo E, VillamizarPena R, Holguin-Rivera Y, Escalera-Antezana JP, et al. Clinical, laboratory and imaging features of COVID-19: a systematic review and meta-analysis. Travel Med Infect Dis. 2020:34:101623.

6. Onder G, Rezza G, Brusaferro S. Case-fatality rate and characteristics of patients dying in relation to COVID-19 in Italy. JAMA. 2020.

7. Rajgor DD, Lee MH, Archuleta S, Bagdasarian N, Quek SC. The many estimates of the COVID-19 case fatality rate. Lancet Infect Dis. 2020;S14733099(20)30244-9.

8. Moher D, Liberati A, Tetzlaff J, Altman DG, PRISMA Group. Preferred reporting items for systematic reviews and meta-analyses: the PRISMA statement. PLoS Med. 2009;6(7):e1000097.

9. World Health Organization. Clinical management of severe acute respiratory infection (SARI) when COVID-19 disease is suspected: Interim guidance. Accessed: March 2020. WHO REFERENCE NUMBER: WHO/2019-nCoV/clinical/ 2020.42020.

10. Metlay JP, Waterer GW, Long AC, Anzueto A, Brozek J, Crothers K, et al. Diagnosis and treatment of adults with community-acquired pneumonia. An official clinical practice guideline of the American Thoracic Society and Infectious Diseases Society of America. Am J Respir Crit Care Med. 2019; 200(7):e45-67.

11. National Health Commission of the People's Republic of China. The notice of launching guideline on diagnosis and treatment of the novel coronavirus pneumonia (5th edition). (Accessed 24 Mar 2020, at http://www.nhc.gov.cn/ yzygj/s7653p/202002/3b09b894ac9b4204a79db5b8912d4440.shtml).

12. Slim K, Nini E, Forestier D, Kwiatkowski F, Panis Y, Chipponi J. Methodological index for non-randomized studies (minors): development and validation of a new instrument. ANZ J Surg. 2003;73(9):712-6.

13. Higgins J, Altman D, Sterne J. Assessing risk of bias in included studies. Cochrane Handbook for Systematic Reviews of Interventions version 5202017.

14. Force ADT, Ranieri VM, Rubenfeld GD, Thompson BT, Ferguson ND, Caldwell $E$, et al. Acute respiratory distress syndrome: the Berlin definition. JAMA. 2012;307(23):2526-33. 
15. Rhodes A, Evans LE, Alhazzani W, Levy MM, Antonelli M, Ferrer R, et al. Surviving Sepsis Campaign: international guidelines for management of sepsis and septic shock: 2016. Crit Care Med. 2017;45(3):486-552.

16. Summary of Recommendation Statements. Kidney Int Suppl (2011). 2012; 2(1):8-12.

17. Thygesen K, Alpert JS, Jaffe AS, Chaitman BR, Bax JJ, Morrow DA, et al. Fourth universal definition of myocardial infarction (2018). Eur Heart J. 2019; 40(3):237-69.

18. Wada H, Thachil J, Di Nisio M, Mathew P, Kurosawa S, Gando S, et al. Guidance for diagnosis and treatment of DIC from harmonization of the recommendations from three guidelines. J Thromb Haemost. 2013.

19. Thachil J, Tang N, Gando S, Falanga A, Cattaneo M, Levi M, et al. ISTH interim guidance on recognition and management of coagulopathy in COVID-19. J Thromb Haemost. 2020.

20. Schulman S, Kearon C. Subcommittee on Control of Anticoagulation of the Scientific Standardization Committee of the International Society on Thrombosis Haemostasis. Definition of major bleeding in clinical investigations of antihemostatic medicinal products in non-surgical patients. J Thromb Haemost. 2005;3(4):692-4.

21. Verity R, Okell LC, Dorigatti I, Winskill P, Whittaker C, Imai N, et al. Estimates of the severity of coronavirus disease 2019: a model-based analysis. Lancet Infect Dis. 2020.

22. R Core Team (2019). R: a language and environment for statistical computing. R Foundation for statistical computing, Vienna, Austria. URL https://www.R-project.org/2019).

23. Cao B, Wang Y, Wen D, Liu W, Wang J, Fan G, et al. A trial of Lopinavirritonavir in adults hospitalized with severe Covid-19. N Engl J Med. 2020; 382(19):1787-1799.

24. Cao J, Tu WJ, Cheng W, Yu L, Liu YK, Hu X, et al. Clinical features and shortterm outcomes of 102 patients with corona virus disease 2019 in Wuhan, China. Clin Infect Dis. 2020;ciaa243.

25. Chen J, Qi T, Liu L, Ling Y, Qian Z, Li T, et al. Clinical progression of patients with COVID-19 in Shanghai. China. J Infect. 2020;80(5):e1-e6.

26. Chen T, Dai Z, Mo P, Li X, Ma Z, Song S, et al. Clinical characteristics and outcomes of older patients with coronavirus disease 2019 (COVID-19) in Wuhan, China (2019): a single-centered, retrospective study. J Gerontol A Biol Sci Med Sci. 2020;glaa089.

27. Cui S, Chen S, Li X, Liu S, Wang F. Prevalence of venous thromboembolism in patients with severe novel coronavirus pneumonia. J Thromb Haemost. 2020

28. Fan $Z$, Chen L, Li J, Cheng X, Jingmao Y, Tian C, et al. Clinical features of COVID19-related liver damage. Clin Gastroenterol Hepatol. 2020;18(7):1561-1566.

29. Feng $Y$, Ling Y, Bai T, Xie Y, Huang J, Li J, et al. COVID-19 with different severity: a multi-center study of clinical features. Am J Respir Crit Care Med. 2020;201(11):1380-1388.

30. Gao L, Jiang D, Wen XS, Cheng XC, Sun M, He B, et al. Prognostic value of NT-proBNP in patients with severe COVID-19. Respir Res. 2020;21(1):83.

31. Grasselli G, Zangrillo A, Zanella A, Antonelli M, Cabrini L, Castelli A, et al. Baseline characteristics and outcomes of 1591 patients infected with SARSCoV-2 admitted to ICUs of the Lombardy region, Italy. JAMA. 2020;323(16): 1574-1581.

32. Grein J, Ohmagari N, Shin D, Diaz G, Asperges E, Castagna A, et al. Compassionate use of remdesivir for patients with severe Covid-19. N Engl J Med. 2020;NEJMoa2007016.

33. Guan WJ, Liang WH, Zhao Y, Liang HR, Chen ZS, Li YM, et al. Comorbidity and its impact on 1590 patients with Covid-19 in China: a nationwide analysis. Eur Respir J. 2020;55(5):2000547.

34. Guan WJ, Ni ZY, Hu Y, Liang WH, Ou CQ, He JX, et al. Clinical characteristics of coronavirus disease 2019 in China. N Engl J Med. 2020;382(18):1708-1720.

35. Guo T, Fan Y, Chen M, Wu X, Zhang L, He T, et al. Cardiovascular implications of fatal outcomes of patients with coronavirus disease 2019 (COVID-19). JAMA Cardiol. 2020;e201017

36. Han H, Xie L, Liu R, Yang J, Liu F, Wu K, et al. Analysis of heart injury laboratory parameters in 273 COVID-19 patients in one hospital in Wuhan, China. J Med Virol. 2020;10.1002/jmv.25809.

37. Jin X, Lian JS, Hu JH, Gao J, Zheng L, Zhang YM, et al. Epidemiological, clinical and virological characteristics of 74 cases of coronavirus-infected disease 2019 (COVID-19) with gastrointestinal symptoms. Gut. 2020;69(6): 1002-1009.

38. Klok FA, Kruip M, van der Meer NJM, Arbous MS, Gommers D, Kant KM, et al. Incidence of thrombotic complications in critically ill ICU patients with COVID-19. Thromb Res. 2020;S0049-3848(20)30120-1.
39. Li R, Tian J, Yang F, Lv L, Yu J, Sun G, et al. Clinical characteristics of 225 patients with COVID-19 in a tertiary hospital near Wuhan, China. J Clin Virol. 2020;127:104363.

40. Li X, Xu S, Yu M, Wang K, Tao Y, Zhou Y, et al. Risk factors for severity and mortality in adult COVID-19 inpatients in Wuhan. J Allergy Clin Immunol. 2020:S0091-6749(20)30495-4.

41. Lian J, Jin X, Hao S, Cai H, Zhang S, Zheng L, et al. Analysis of epidemiological and clinical features in older patients with corona virus disease 2019 (COVID-19) out of Wuhan. Clin Infect Dis. 2020;ciaa242.

42. Liu K, Chen Y, Lin R, Han K. Clinical features of COVID-19 in elderly patients: a comparison with young and middle-aged patients. J Inf Secur. 2020; 80(6): e14-e18.

43. Liu K, Fang YY, Deng Y, Liu W, Wang MF, Ma JP, et al. Clinical characteristics of novel coronavirus cases in tertiary hospitals in Hubei Province. Chin Med J. 2020;133(9):1025-1031.

44. Liu W, Tao ZW, Lei W, Ming-Li Y, Kui L, Ling Z, et al. Analysis of factors associated with disease outcomes in hospitalized patients with 2019 novel coronavirus disease. Chin Med J. 2020;133(9):1032-1038.

45. Qian GQ, Yang NB, Ding F, Ma AHY, Wang ZY, Shen YF, et al. Epidemiologic and clinical characteristics of 91 hospitalized patients with COVID-19 in Zhejiang, China: A retrospective, multi-centre case series. QJM. 2020;hcaa089.

46. Shi H, Han X, Jiang N, Cao Y, Alwalid O, Gu J, et al. Radiological findings from 81 patients with COVID-19 pneumonia in Wuhan, China: a descriptive study. Lancet Infect Dis. 2020;20(4):425-34.

47. Shi S, Qin M, Shen B, Cai Y, Liu T, Yang F, et al. Association of cardiac injury with mortality in hospitalized patients with COVID-19 in Wuhan, China. JAMA Cardiol. 2020;e200950.

48. Tang N, Bai H, Chen X, Gong J, Li D, Sun Z. Anticoagulant treatment is associated with decreased mortality in severe coronavirus disease 2019 patients with coagulopathy. J Thromb Haemost. 2020;18(5):1094-9.

49. Tang N, Li D, Wang X, Sun Z. Abnormal coagulation parameters are associated with poor prognosis in patients with novel coronavirus pneumonia. J Thromb Haemost. 2020;18(4):844-7.

50. Tian S, Hu N, Lou J, Chen K, Kang X, Xiang Z, et al. Characteristics of COVID19 infection in Beijing. J Inf Secur. 2020;80(4):401-6.

51. Wang D, Hu B, Hu C, Zhu F, Liu X, Zhang J, et al. Clinical Characteristics of 138 Hospitalized Patients With 2019 Novel coronavirus-infected pneumonia in Wuhan, China. JAMA 2020:323(11):1061-1069.

52. Wang L, He W, Yu X, Hu D, Bao M, Liu H, et al. Coronavirus disease 2019 in elderly patients: characteristics and prognostic factors based on 4-week follow-up. J Inf Secur. 2020; 80(6):639-645.

53. Wang L, Li X, Chen H, Yan S, Li D, Li Y, et al. Coronavirus Disease 19 Infection Does Not Result in Acute Kidney Injury: An Analysis of 116 Hospitalized Patients from Wuhan, China. Am J Nephrol. 2020:51(5):343-348.

54. Wang Y, Lu X, Chen H, Chen T, Su N, Huang F, et al. Clinical course and outcomes of 344 intensive care patients with COVID-19. Am J Respir Crit Care Med. 2020; 201(11):1430-1434

55. Wang Y, Dong C, Hu Y, Li C, Ren Q, Zhang X, et al. Temporal changes of CT findings in 90 patients with COVID-19 pneumonia: a longitudinal study. Radiology. 2020;200843.

56. Wang Z, Yang B, Li Q, Wen L, Zhang R. Clinical features of 69 cases with coronavirus disease 2019 in Wuhan, China. Clin Infect Dis. 2020;ciaa272.

57. Wu C, Chen X, Cai Y, Xia J, Zhou X, Xu S, et al. Risk factors associated with acute respiratory distress syndrome and death in patients with coronavirus disease 2019 pneumonia in Wuhan, China. JAMA Intern Med. 2020;e200994.

58. Wu J, Liu J, Zhao X, Liu C, Wang W, Wang D, et al. Clinical characteristics of imported cases of COVID-19 in Jiangsu Province: a multicenter descriptive study. Clin Infect Dis. 2020;ciaa199.

59. $X u X W, W u X X$, Jiang $X G, X u K J$, Ying $L J, M a C L$, et al. Clinical findings in a group of patients infected with the 2019 novel coronavirus (SARS-Cov-2) outside of Wuhan, China: retrospective case series. BMJ. 2020;368:m606.

60. Yang W, Cao Q, Qin L, Wang X, Cheng Z, Pan A, et al. Clinical characteristics and imaging manifestations of the 2019 novel coronavirus disease (COVID19):a multi-center study in Wenzhou city, Zhejiang. China J Infect. 2020; 80(4):388-93.

61. Yang $X, Y u Y, X u$ J, Shu H, Xia J, Liu H, et al. Clinical course and outcomes of critically ill patients with SARS-CoV-2 pneumonia in Wuhan, China: a singlecentered, retrospective, observational study. Lancet Respir Med. 2020;8(5):475-481.

62. Yang $X$, Yang Q, Wang Y, Wu Y, Xu J, Yu Y, et al. Thrombocytopenia and its association with mortality in patients with COVID-19. J Thromb Haemost. 2020 . 
63. Zhang J, Wang X, Jia X, Li J, Hu K, Chen G, et al. Risk factors for disease severity, unimprovement, and mortality in COVID-19 patients in Wuhan, China. Clin Microbiol Infect. 2020; 26(6):767-772.

64. Zhang L, Yan X, Fan Q, Liu H, Liu X, Liu Z, et al. D-dimer levels on admission to predict in-hospital mortality in patients with Covid-19. J Thromb Haemost. 2020.

65. Zhou F, Yu T, Du R, Fan G, Liu Y, Liu Z, et al. Clinical course and risk factors for mortality of adult inpatients with COVID-19 in Wuhan, China: a retrospective cohort study. Lancet. 2020;395(10229):1054-62.

66. Vincent JL, Sakr Y, Singer M, Martin-Loeches I, Machado FR, Marshall JC, et al. Prevalence and outcomes of infection among patients in intensive care units in 2017. JAMA. 2020;323(15):1478-1487.

67. Vincent $\mathrm{JL}$, Taccone FS. Understanding pathways to death in patients with COVID-19. Lancet Respir Med. 2020;8(5):430-432.

68. Cao Y, Li L, Feng Z, Wan S, Huang P, Sun X, et al. Comparative genetic analysis of the novel coronavirus (2019-nCoV/SARS-CoV-2) receptor ACE2 in different populations. Cell Discov. 2020;6:11.

\section{Publisher's Note}

Springer Nature remains neutral with regard to jurisdictional claims in published maps and institutional affiliations.

Ready to submit your research? Choose BMC and benefit from:

- fast, convenient online submission

- thorough peer review by experienced researchers in your field

- rapid publication on acceptance

- support for research data, including large and complex data types

- gold Open Access which fosters wider collaboration and increased citations

- maximum visibility for your research: over $100 \mathrm{M}$ website views per year

At $\mathrm{BMC}$, research is always in progress.

Learn more biomedcentral.com/submissions 